\title{
Notas sobre construções reflexivas através do teatro do oprimido enquanto ferramenta pedagógica
}

ENSAIO DE UM-NÓS: notas sobre construções reflexivas através do teatro do oprimido enquanto ferramenta pedagógica

ESSAY OF ONE OF US: notes on reflexive constructions through the theater of the oppressed as a pedagogical tool

\section{Lana Maiara Saraiva Furtado}

lanamaiara@yahoo.com.br

Licenciada em Artes Visuais e acadêmica de Teatro pela Universidade Federal do Amapá

\section{Resumo:}

Das possibilidades de utilização do teatro enquanto ferramenta de reflexão ou prática pedagógica, através do Teatro do Oprimido desenvolvido por Augusto Boal voltado para a formação de acadêmicos de teatro visando a atentar às situações de opressões no dia-a-dia. Este artigo tem como objetivo discutir essa prática de teatro que torna o espectador parte do espetáculo dandoIhe liberdade e ação. Tendo como referencial teórico: Boal (1991;2009) e Filho e Marques (2012) como base teórica das formulações e estudos sobre o Teatro do oprimido e suas técnicas; Le Breton (2007) sustenta questões do corpo e experiência corporal; Pavis (2008) que aborda a expressão dentro do teatro e das artes e Roubine (1998) nos ampara com questões de encenação enquanto linguagem. Desse processo prático-teórico que resultou em um espetáculo de experimentos, no qual se utilizou algumas de suas modalidades entre elas: o Teatro-Imagem e Teatro-Jornal, mostrando aos futuros professores o quanto o T.O tem enquanto ferramenta de construção do pensamento crítico.

Palavras-chave: Educação, T.O., Metodologia de ensino, experimento.

\section{Abstract:}

The possibility of using theater as a tool for reflection or pedagogical practice, through the Theater of the Oppressed developed by Augusto Boal aimed at the training of theater academics in order to attend to situations of oppression in everyday life. This article aims to discuss this practice of theater that makes the viewer part of the show giving him freedom and action. Having as theoretical theorist: Boal (1991; 2009) and Filho and Marques (2012) as theoretical basis of formulations and studies on the Theater of the oppressed and its techniques; Le Breton (2007) sustains body issues and bodily experience; Pavis (2008), which deals with expression within the theater and the arts, and Roubine (1998) supports us with issues of staging as a language. From this practical-theoretical process that resulted in a show of experiments, in which some of their modalities were used: Theater-Image and Theater-Journal, showing future teachers how much the T.O has as a tool for the construction of critical thinking.

Keywords: Education, T.O., teaching methodology, experiment.

O artigo presente tem como intuito discutir a utilização do Teatro do Oprimido enquanto metodologia de ensino para a formação de futuros professores. Através das práticas em sala de 
aula desenvolvidas durante o 2으 semestre de 2017 com uma turma do curso de Licenciatura em Teatro da Universidade Federal do Amapá - UNIFAP, no decorrer da disciplina Prática Pedagógica II, ministrada pelo Professor José Flávio Gonçalves da Fonseca. Com o estudo de algumas das técnicas pertencentes ao Teatro do Oprimido, este que vem se construindo em forma de relato fala mais das vivencias e experimentos que envolvem o espectador na trama. Conhecemos as técnicas do Teatro do Oprimido através da Figura 1 que ilustra como o conhecimento é repassado através do Teatro. O primeiro ponto a ser observado enquanto aspecto de modificação do cotidiano acadêmico, seria a mudança do espaço de trabalho, ou seja, a sala de aula. O local foi pensado para sua ampliação retirando os obstáculos, as carteiras foram movidas e esta atitude da saída desses elementos por si só já se torna uma quebra na estrutura padrão do que seria uma aula "normal". Seguindo a linha de pensamento de Augusto Boal (1991) na qual o teatro se torna uma arma de libertação, pensamos aqui em corpos acadêmicos que se comportam e conectam com outros corpos e assim tomam outras formas e forças através desses contatos. Entendendo que através desses experimentos que envolvem a esfera teatral, os corpos mudam-se a si mesmos e aos outros conforme sua interação com o ambiente, com o todo (LE BRETON, 2007).

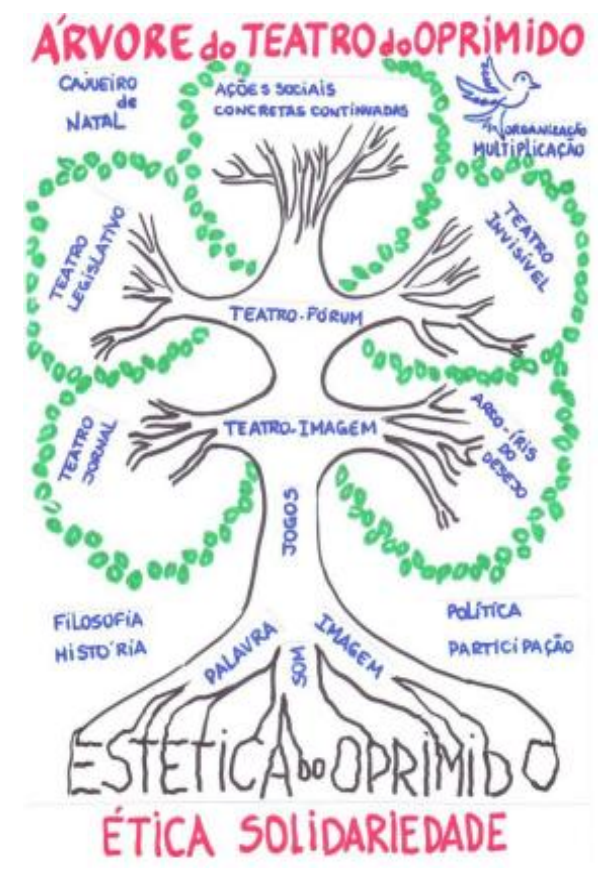

Figura 1 - Árvore do Teatro do Oprimido com as técnicas que estudamos no decorrer das aulas Fonte: Imagem retirada da internet 


\section{ENSAIO DE UM-DE-NÓS: Notas sobre construções reflexivas através do teatro do oprimido enquanto ferramenta pedagógica}

A proposta da utilização do Teatro do Oprimido como ferramenta de prática pedagógica para a possibilidade de aplicação em sala de aula por nós acadêmicos, futuro profissionais visando a participação dos alunos de modo crítico-artístico, portanto nos submetendo esses processos de experimentações e experiências na academia. Além de pensar esse espaço físico-arquitetônico, apreendemos sobre o que seria o Teatro do Oprimido, quais suas técnicas e sua aplicabilidade em todas as esferas sociais, utilizando as vivencias dos integrantes, nesse caso, nossas vivências. Daqui alguns anos, serão nossas experiências em sala de aula e nesse intercâmbio de experiências temos que ter olhares mais cuidadosos para com o outro. Pois se faz necessário que a sala de aula seja um lugar de construção e não somente de transmissão de conhecimento.

Das experiências adquiridas durante os experimentos, podemos observar o processo todo tomando forma, e suas subjetividades quanto a aplicabilidade das técnicas do Teatro do Oprimido - além das práticas teatrais - envolvendo uma questão social, além da construção de argumentos e histórias contadas com a apropriação do acesso à memória. Essa rememorização - no sentindo de visitar uma memória de situação vivida - assim como a construção do experimento, tomando como base as histórias de opressão vividas por nós, foram orientadas e supervisionadas pelo professor Flávio, como podemos ver na Figura 2, ele esteve presente em todos momentos enquanto professor/orientador e diretor/mediador. Sua função seria a de acionar problematizações acerca de várias temáticas sociais que constitui T.O. enquanto método político também além de ser educativo. Assim o refletir sobre esses questionamentos e/ou situações cotidianas contribuem para o confrontar desses discursos e ações que já se tornaram "naturais". A educação é concebida enquanto práxis de ação/reflexão/ação sobre o mundo, o conceito de opressão atrela-se às relações sociais de poder e a prática educativa aos atos coletivos de apropriação do conhecimento sistematizado e de transformação social (FILHO \& MARQUES, 2012, p. 3). 


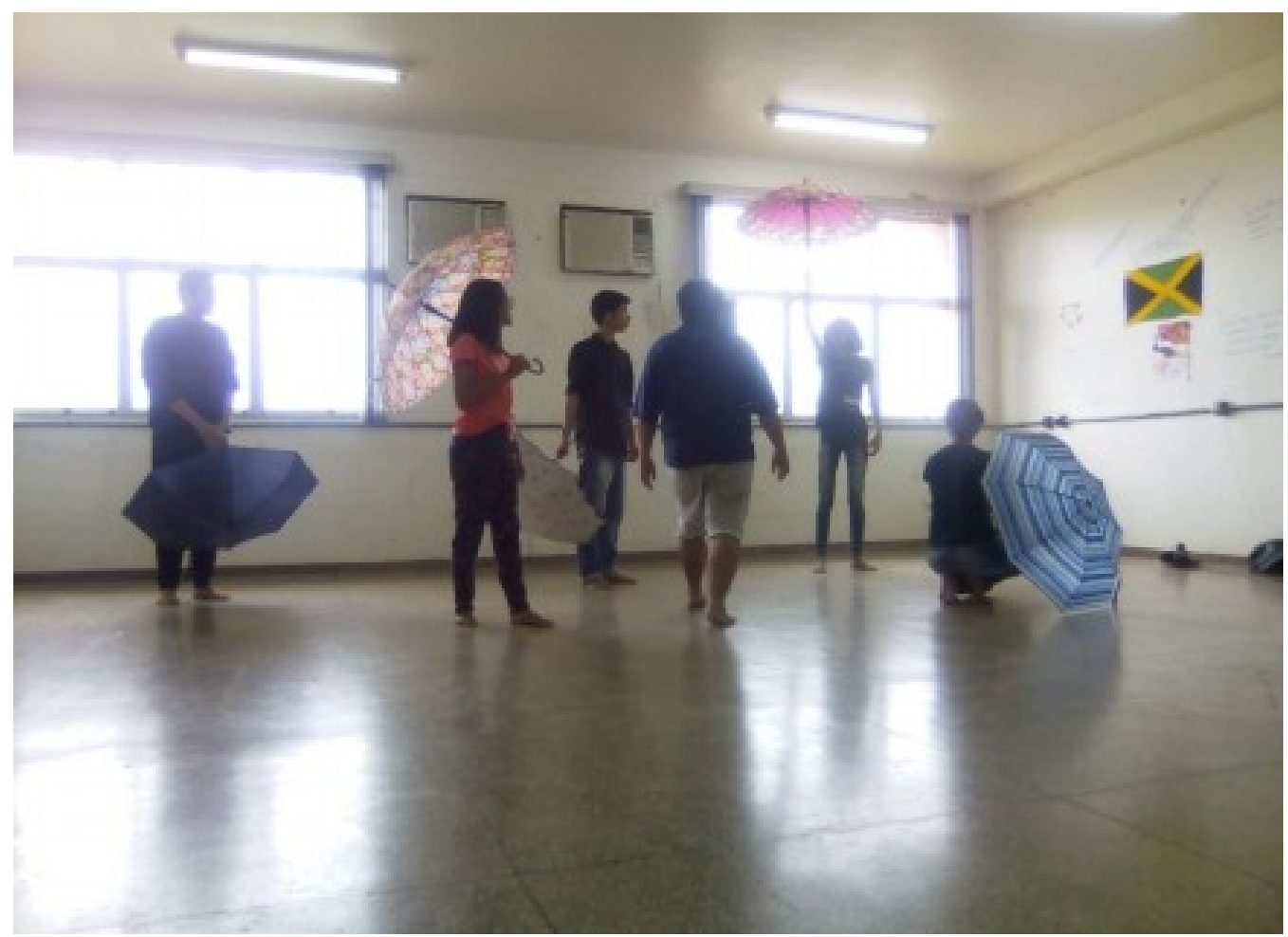

Figura 2 - Registro fotográfico de um dia de preparação do experimento

A educação acaba por se tornar mediadora das ações e reflexões da vida e do mundo, e somente através dela que se pode desconstruir essas relações de poder que atingem o social, mas que afeta muito mais a minoria, e por meio dessas práticas educativas se libertar dessas amarras dessas relações que são construídas socialmente e sistematizam todo o conhecimento como uma forma maior de mandado e obediência. Quanto ao nosso envolvimento em aula, desses contatos com os outros e suas histórias, as potencialidades que ganham nos direcionam para a desses estereótipos que carregávamos, estereótipos estes que envolvem racismo, machismo, entre outras situações de opressões com crianças, mulheres, negros, LGBTs etc. que ocorrem no dia-adia das mais variadas formas, seja em uma fala, em uma atitude e no pensamento, alertando para a importância de sempre se debater essas discriminações.

Passamos pela primeira etapa do plano que Boal estabelece com o T.O. para a conversão desse espectador em ator. A primeira etapa seria a do Conhecimento do Corpo na qual, junto ao professor trabalhamos os limites e possibilidades de exercícios com o corpo, para desabituar esse corpo atrofiado por pelas ações naturais, maneira como estamos habituados à ações cotidianascomo andar, sentar, projetar a voz entre outros. Conhecer o próprio corpo, tocá-lo e deixar-se tocar foi uma etapa bastante difícil, os exercícios que em sua maioria seriam parte de jogos foram 


\section{ENSAIO DE UM-DE-NÓS: \\ Nołas sobre construções reflexivas através do teatro do oprimido enquanto \\ ferramenta pedagógica}

essenciais para atingirmos esse conhecer-se a si mesmo e conhecer o corpo e limites do outro, estreitando mais a relação corpo-espaço-outro.

Depois desse corpo ter entrado no exercício de se desprender das "amarras" através da prática do conhecer-se e consequentemente, criar consciência desse corpo durante exercícios corporais, de respiração, de concentração, de jogos com o outro e consigo mesmo e outros atos de chegar ao limite de seu próprio exercitar. Passamos assim para a segunda etapa em outro momento de aula, o: Tornar o Corpo Expressivo. Aqui entra a reflexão do que seria expressão dentro do campo artístico-cênico, que utiliza a expressão "ex-pressar" como denominação e função do ator revelador que expulsa do/e através do corpo aquilo que já não the cabe mais, aquilo que quer se mostrar, se libertar, expressando através do corpo e gestos suas significâncias e sentidos de formas divergentes as usuais e cotidianas (BOAL, 1991). Exteriorizar o que é oculto de forma não habitual e subjetiva, como Pavis (2008) fala, exteriorização do que lhe é oculto que seja capaz de representar a vida e sua significação por meio da expressividade gestual e corporal do ator.

Expressões corporais as quais com a prática fomos nos habituando às novas formas de pensar o corpo e sua potência imagética, além é claro, das possibilidades de improvisos e raciocínio rápido e tomada de decisões simultâneas. Nos experimentos o corpo, se tornou objeto divergente a ele, outro animal, por vezes extensão do corpo alheio e em coletivo um outro corpo, por exemplo a Figura $\mathbf{3}$ de modo imagético nos mostra guarda-chuvas amontoados, mas dentro da cena os integrantes se uniam todos respectivamente após suas falas para o centro do palco, e ali quando o ultimo relato era contado e o ator se colocava dentro dessas armações, todos movimentavam seus objetos cênicos e emitiam som que imitavam um coração pulsando, assim os movimentos acompanhavam esse som. Pensando todas as ligações do corpo e todos os sentidos, voz, escuta, atenção, visão, percepções etc. aqueles corpos se moldaram em um para transmitir e revelar um novo ato. 


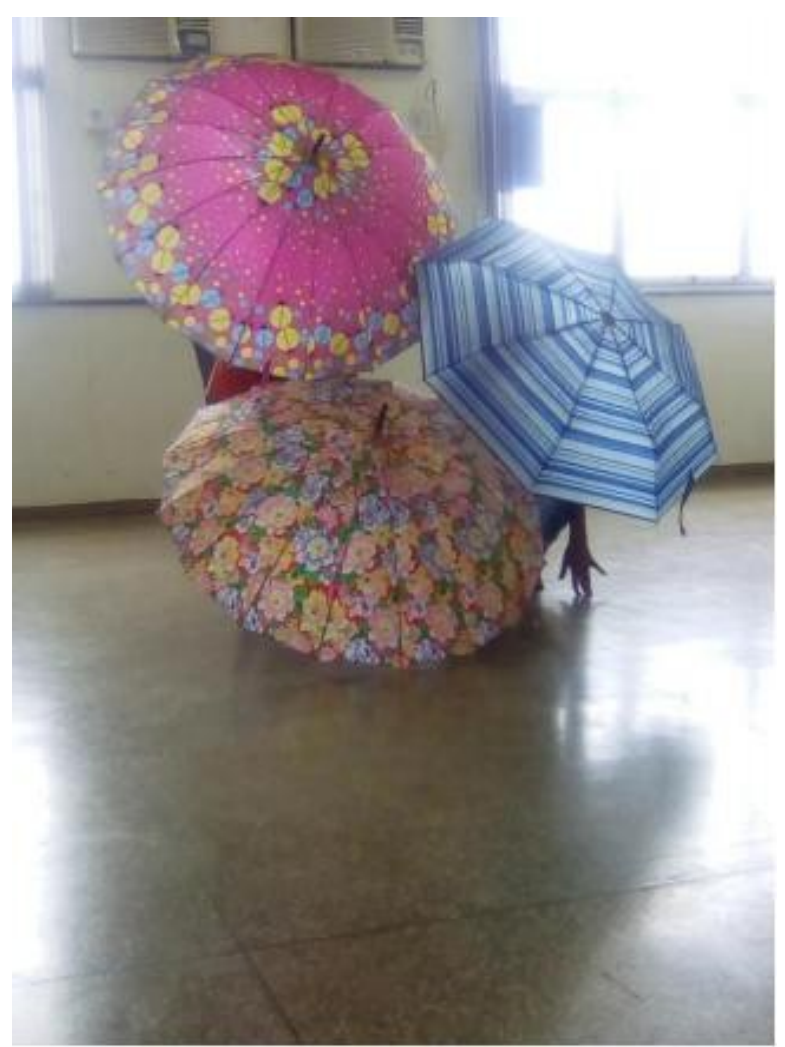

Figura 3 - Registro fotográfico de ensaio, os corpos que se transformam em um só

Os corpos que se envolvem e se tornam um só, corpos que se transfiguram, modificam o espaço, entre outras possibilidades de expressões corporais que vínhamos construindo com os processos. Pois a expressão corporal "[...] sensibiliza os indivíduos para suas possibilidades motoras e emotivas, para seu esquema corporal e para sua faculdade de projetar este esquema na sua interpretação. " (PAVIS, 2008, p. 155) A partir desse esquema corporal que chegamos a terceira etapa: O Teatro como Linguagem, na qual deve-se projetar e "praticar o teatro e suas formas como linguagem viva e presente " (BOAL, 1991, p. 143) através de improvisos individuais e em coletivo. Como os experimentos em sala de aula exemplificado na Figura 4, foram convidados acadêmicos a contarem suas histórias de opressão de maneira livre, e outro acadêmico viria a se tornar o ator para a encenação tendo como base a história revisitada, por meio de falas que ocorreram como relato de opressão durante a cena, esses relatos serviram para a construção do experimento do Teatro-Fórum. Lembrando sempre que em situação de opressão vivenciada e ali experenciada em cena o oprimido não deve se tornar opressor, pois isso não elimina ou resolve algo, e sim inverte-se os papéis. E o que o T.O. discute a resolução através da eliminação total de opressão através da educação e dentro de limites de boa convivência. Outras questões seriam: de 


\section{ENSAIO DE UM-DE-NÓS: \\ Notas sobre construções reflexivas através do teatro do oprimido enquanto \\ ferramenta pedagógica}

onde parte a opressão? e o porquê? Para assim se chegar a um consenso de problematização e discussão com todos os envolvidos.

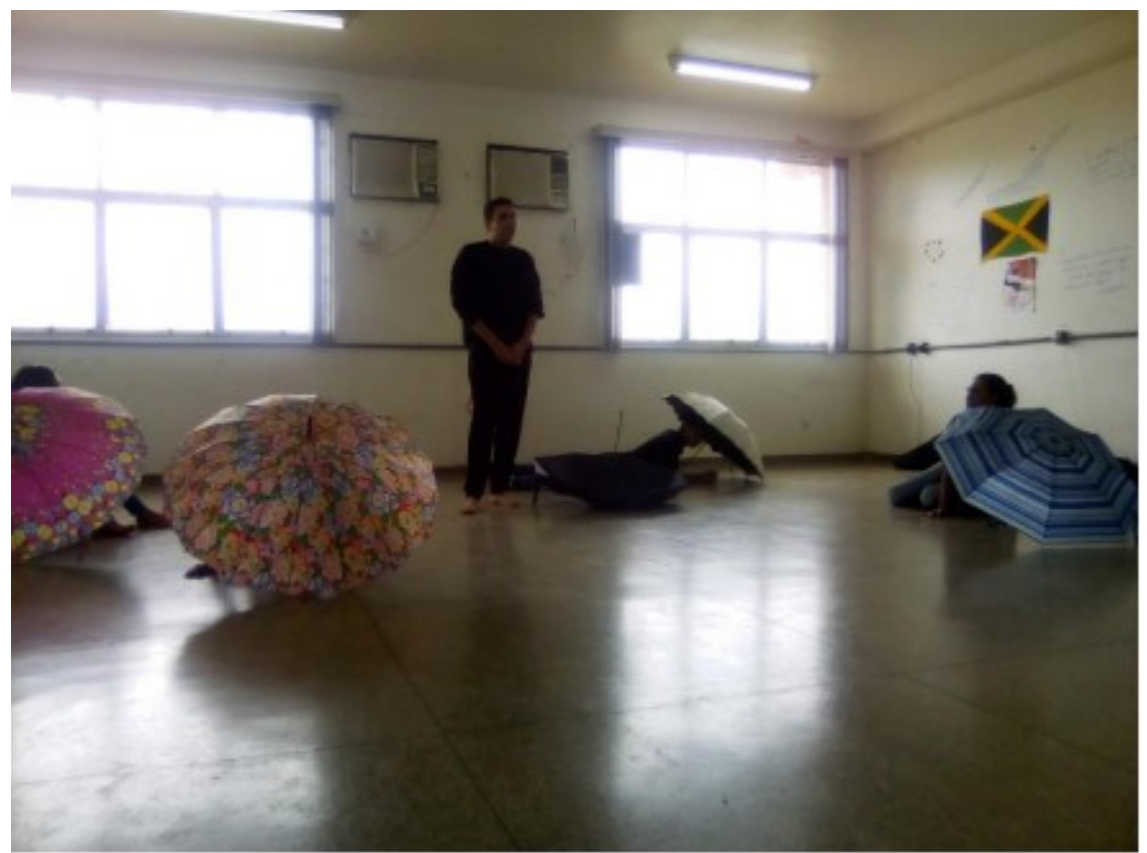

Figura 4 - Registro fotográfico das ações de improviso através das histórias contadas pelos colegas de classe

A proposta da Mostra Poética Política de Teatro do Oprimido, evento ao qual nossa turma, a turma 2017 de curso de Teatro da UNIFAP, apresentara como trabalho final de disciplina, apresentar o resultado dos experimentos dentro das técnicas do T.O. como uma forma dinâmica e crítica problematizar essas questões de opressões vivenciadas por todos nós no nosso dia-a-dia. Dentre as técnicas do T.O. utilizamos o Teatro-Imagem, no qual o objetivo seria o de ensaiar uma transformação da realidade através da imagem corporal. Montar um espetáculo conosco e com nossas histórias para sensibilizar as pessoas, e convidá-las a serem atores e tomadores de ações dentro do espetáculo. O Espect.-ator monta a imagem que represente a opressão discutida, e agora o que antes era a imagem de opressão, outra pessoa molda a imagem para uma situação ideal resolvendo a opressão através da imagem composta pelos atores inertes. O tema por nós escolhido dentre vários relatos e conversas em sala de aula que foram desde assédio, discriminação, autoritarismo paternais, militarismo disciplina, homofobia etc. Optamos por uma notícia do jornal sobre abuso de autoridade policial, assim montamos o espetáculo de Teatro 
Jornal ${ }^{1}$ titulado: POLICIA, PARA! QUEM PRECISA? Como mostra o cartaz do espetáculo na Figura 5. Utilizamos a leitura simples, a improvisação - recriar uma cena a partir das informações do noticiário; a ação paralela - na qual cenas vão se construindo durante a leitura da publicação; ainda contamos com música e imagem em projeção para explicitar a ideia que a notícia quer repassar ao leitor.

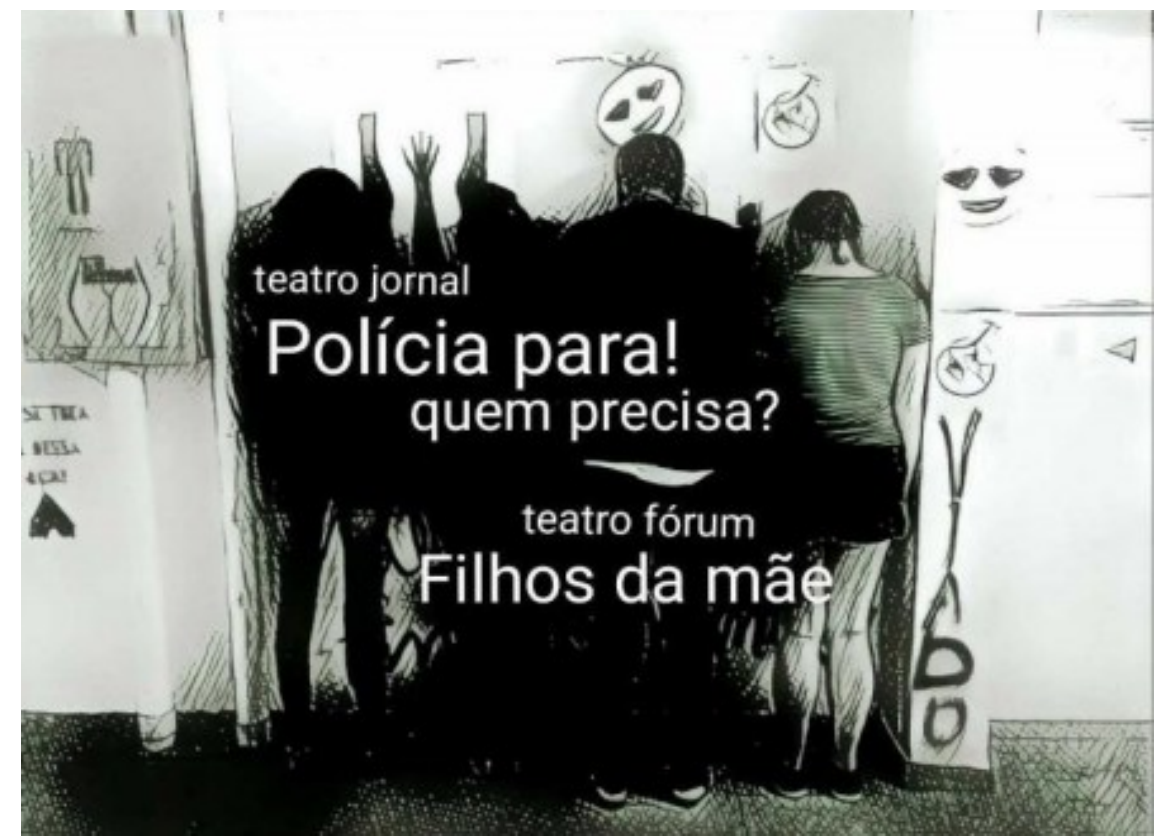

Figura 5 - Cartaz de divulgação do experimento

Assim discutir de forma teatral sobre a situação de opressão sofrida a partir da força policial em exercício. Um dos atos dentro da relação de opressão dentro da construção social que conhecemos, encenamos o militarismo e sua relação com a educação, ideia de disciplina e formalismo hierárquico. Mas também podemos levar pela relação de poder - aluno/ professorcomo forma de opressão à liberdade de pensamento e corporal, como a Figura 6 nos mostra uma de nossas colegas se voluntariou para o ato de corte de cabelo, algo que afeta profundamente a ideia de uniformização nas escolas - garotos cortam o cabelo mais baixo, garotas prendem os cabelos.

\footnotetext{
${ }^{1}$ Desenvolvido por Boal no Teatro de Arena em São Paulo, essa modalidade dentro do T.O. pretende transformar noticiais de jornal quaisquer em ações dramáticas.
} 


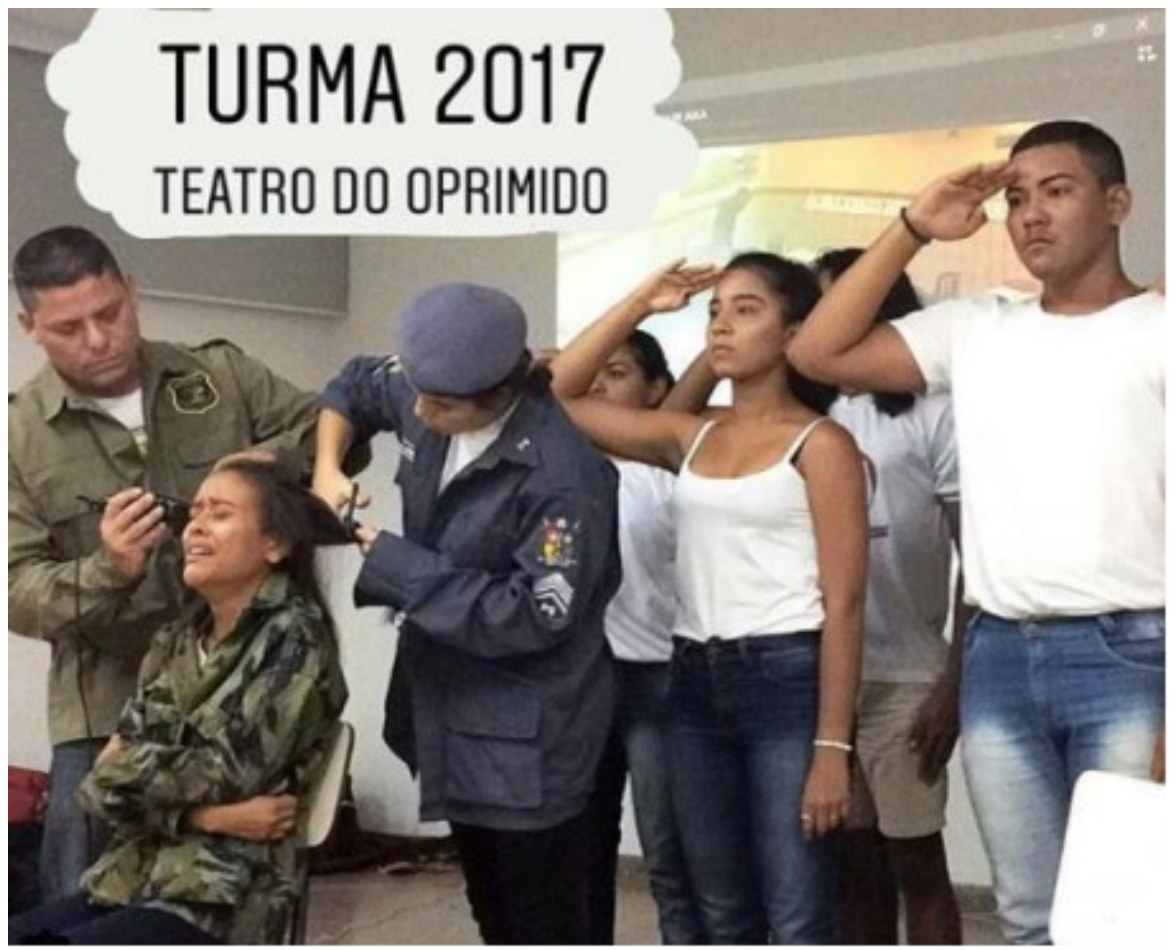

Figura 6- Registro fotográfico do experimento em apresentação para o público

Se para Roubine (1998) o fenômeno Teatro é produzido através do contato do ator com o espectador, já no Teatro do Oprimido vemos uma revolução, o Teatro é produzido através da ação do espectador que se converte em ator. Com seu caráter militante, político-social, educativo etc. o T.O. direciona discussão e questionamentos que problematizam discordâncias quanto à um sistema hegemônico que desvaloriza uma massa minoritária. O nosso papel enquanto futuro professores é o de nos tornamos críticos de nosso tempo e perpetuar a valorização de todos por igual, e tudo através das ferramentas que temos em mãos, a sabedoria. A escola deve ser o local a ser debatidas e confrontadas situações de opressões para a formação de mais outros seres pensantes, pulsantes e críticos de seus tempos.

\section{Considerações finais}

Conhecer Augusto Boal e suas técnicas teatrais dentro do Teatro do Oprimido foi deveras uma das experiências mais envolventes que a turma presenciou e participou. A potencialidade que o T.O. nos possibilita para o trabalho em quaisquer meios amplia a visão de teatro que 
conhecíamos, o teatro grego onde o espectador é somente parte passiva e sem voz, e direcionar as técnicas enquanto ferramentas de discussão em sala de aula problematizando através de situações cotidianas fortifica o pensamento de sociedade que queremos para nós mesmos e para as pessoas ao nosso redor. Quando a platéia se choca com o ato de cortar o cabelo, a ironia das falas das personagens, as construções de imagens no decorrer dos atos isso reverbera de forma significativa o papel deste que assiste. E se torna mais impactante para ele, quando este vê a possibilidade de mudar a trajetória de uma situação que quase todos nós passamos - o se colocar na "pele" do outro e poder responder no local do outro-, a tomada de decisão e ação é aos poucos reconstruída. Essas ações que fazem a diferença para a vida social, as problematizações levantadas, as indagações que não se fecham etc. são elas que movem o mundo. E o professor que utiliza as artes para a desconstrução desses sistemas hegemônicos padronizadores tende a crescer mais ainda enquanto ser humano e profissional, e uma experiência dessas durante a graduação só tende a tornarem pessoas e profissionais responsáveis e conscientes.

\section{Referências}

BOAL, Augusto. Poética Do Oprimido. Pp. 133 A 230. IN:BOAL, Augusto. Teatro Do Oprimido E Outras Poéticas Políticas. 6a Ed. Editora Civilização Brasileira. Rio De Janeiro, 1991.

A Estética Do Oprimido. Garamound. Rio de Janeiro, 2009.

FILHO, J. P. P; MARQUES, E. M. D. Teatro Do Oprimido E Educação: Perspectivas Para As Práticas

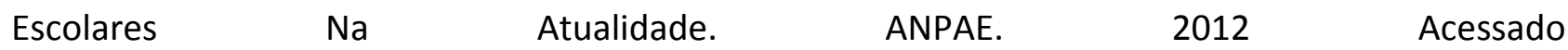
em:(http://www.anpae.org.br/iberoamerican02012/Trabalhos/JosePeixotoFilho res_int GT 1.pdD em 30/01/2018 às 17:30h

LE BRETON, David. A Sociologia Do Corpo. Editora vozes. Petrópolis, RJ, 2007;

PAVIS, Patrice. Dicionário De Teatro. Editora Perspectiva. 3a ed. São Paulo, 2008.

ROUBINE, Jean-Jacques. A Linguagem Da Encenação Teatral. 2a ed. Jorge Zahar Ed. Rio de Janeiro, 1998.

Artigo submetido em 02/11/2018, e aceito em 21/12/2018. 